\title{
The influence of renin angiotensin aldosterone system blockers on asymmetric dimethylarginine levels in patients with chronic glomerulonephritis
}

\author{
Zbigniew Heleniak ${ }^{1 \star}$, Zbigniew Zdrojewski², Piotr Wisniewski³ ${ }^{3}$, Leszek Bieniaszewski ${ }^{4}$, \\ Boleslaw Rutkowski ${ }^{1}$, Alicja Debska-Slizien ${ }^{1}$
}

${ }^{1}$ Department of Nephrology, Transplantology and Internal Medicine, Medical University of Gdansk, Debinki 7 80-952 Gdansk, Poland

${ }^{2}$ Department of Internal Medicine, Connective Tissue Disease and Geriatrics, Medical University of Gdansk, Debinki 7 80-952 Gdansk, Poland

${ }^{3}$ Department of Endocrinology and Internal Medicine, Medical University of Gdansk, Debinki 7 80-952 Gdansk, Poland

${ }^{4}$ Department of Hypertension and Diabetology, Medical University of Gdansk, Debinki 7 80-952 Gdansk, Poland

\section{ARTICLE INFO \\ Received 11 August 2016 \\ Accepted 04 October 2016}

\section{Keywords:}

asymmetric dimethylarginine, proteinuria,

renin angiotensin aldosterone system.

\begin{abstract}
Endothelial dysfunction could be related to the limited availability of nitric oxide (NO). NO is synthesized with the participation of an NO synthase whose activity is inhibited by asymmetric dimethylarginine (ADMA). The synthesis of ADMA is exacerbated by oxidative stress, and several studies have shown the efficacy of drugs acting on the reninangiotensin-aldosterone system (RAAS) (converting enzyme inhibitors and angiotensin II receptor antagonists) in reducing the level of ADMA. The probable mechanism of drug action is a reduction of oxidative stress through a decrease of angiotensin II formation. The aim of this study was to assess the influence of RAAS blockers on the plasma concentration of ADMA in patients with chronic glomerulonephritis (ChGN). The study included 37 patients, placed into group A and group B, depending on the treatment. Both groups were treated with RAAS blockers. In group B, immunosuppressive drugs were additionally administered. The control visits were at the 0,6 and 12 months of observation. In both the studied groups $(\mathrm{A}+\mathrm{B})$, a significant reduction of ADMA ( 0.77 vs $0.4 \mu \mathrm{mol} / 1 ; \mathrm{p}<0.05$ ) was noticed. In patients suffering from $\mathrm{ChGN}$, the use of RAAS blockers resulted in a significant decrease of plasma ADMA concentration, independently of immunosupressive treatment.
\end{abstract}

\section{INTRODUCTION}

Nitric oxide (NO), produced by the endothelial cells of vessels, induces vasodilatation by way of the relaxation of the vascular smooth muscle. In 1992, analogues of L-arginine were first identified in plasma and urine samples. Two of these (L-N-mono-metylarginine (L-NMMA), NG, NGdimethylarginine (Asymmetric dimethylarginine-ADMA), are endogenous inhibitors of NO synthase. ADMA concentrations in human plasma is 10 times greater than L-NMMA, and ADMA is, therefore, considered a very significant endogenous NO synthase (NOS) inhibitor. The synthesis

\footnotetext{
${ }^{\star}$ Corresponding author

e-mail: zth1@gumed.edu.pl;

phone: +48502 987604 (mobile), + 48583492505

fax: + 48583492551
}

of ADMA is exacerbated by oxidative stress, and several studies have shown the efficacy of drugs acting on the reninangiotensin-aldosterone system (RAAS) in reducing the level of ADMA [4,5]. This phenomenon's mechanism is unclear. The probable action of these drugs is the bringing about of a reduction of oxidative stress, by decreasing the formation of angiotensin II.

The aim of this study was to assess the relationship between plasma concentration of ADMA, proteinuria, some other biochemical parameters and blood pressure, in patients with chronic glomerulonephritis (ChGN) who are undergoing medical treatment including RAAS blockade.

\section{MATERIALS AND METHODS}


The study group consisted of 37 adult patients $(26 \mathrm{M}$, $11 \mathrm{~F}$ ) at a mean age of $38.5 \pm 11.5$ (range 22-64) years, suffering from chronic glomerulonephritis $(\mathrm{ChGN})$. The patients presented either a nephrotic (n-14) or a non-nephrotic (n-23) range of proteinuria, and by way of renal biopsy, different types of ChGN were diagnosed. Patients suffering from diabetes mellitus and coronary artery disease were, however, excluded from the study. The control group consisted of 29 healthy volunteers (M-15, F-14) at a mean age $36.4 \pm 9.5$ (range 19-52) years, who were not taking any (even overthe-counter) medication.

The whole study group of patients has been divided further into two groups. Group A (n-17) consisted of patients who were treated with RAAS blockers. These drugs were used separately or together. Patients from Group B (n-20), in addition to RAAS blockers, received immunosuppressive therapy according to indication (Table 1).

Table 1. Treatment schedule

\begin{tabular}{|l|c|c|c|}
\hline $\begin{array}{c}\text { The type } \\
\text { of treatment }\end{array}$ & $\begin{array}{c}\text { Total } \\
(n-37)\end{array}$ & $\begin{array}{c}\text { Group A } \\
(n-17)\end{array}$ & $\begin{array}{c}\text { Group B } \\
(n-20)\end{array}$ \\
\hline ACE inhibitors & $15(40 \%)$ & $6(35 \%)$ & $9(45 \%)$ \\
\hline Sartans & $4(11 \%)$ & 0 & $4(20 \%)$ \\
\hline Double blockade of RAA & $15(40 \%)$ & $11(65 \%)$ & $4(20 \%)$ \\
\hline Statins & $9(24 \%)$ & $4(24 \%)$ & $5(25 \%)$ \\
\hline Diuretics & $16(43 \%)$ & $1(6 \%)$ & $15(75 \%)$ \\
\hline Glucocorticosteroids & $19(51 \%)$ & 0 & $19(95 \%)$ \\
\hline Cyclophosphamide & $4(11 \%)$ & 0 & $4(20 \%)$ \\
\hline Cyclosporin & $1(3 \%)$ & 0 & $1(5 \%)$ \\
\hline
\end{tabular}

The project received the approval of the Medical University of Gdansk Bioethical Committee (NKEBN/289/2007). Both volunteers and patients, after hearing the study protocol, signed written informed consent to participate in the study.

Before the study and after 6 and 12 months, all patients underwent assessment of ADMA plasma concentration, as well as daily blood pressure measuretaken for the following tests: total cholesterol, creatinine, sodium, potassium, CRP, glucose, albumin and fibrinogen, and daily urine protein excretion. In the controls, ADMA measurements were done only once. ADMA concentration measurement was performed using ELISA (Enzyme Linked Immunosorbent Assay) kits (Immunodiagnostik).

Standard descriptive statistics (mean, standard deviation) were calculated. Compliance distribution of the variables with normal distribution was evaluated through analyzing histograms. In situations of nongausian distribution, appropriate transformation functions were applied. Intergroup comparison of variables' normal distribution or similar, was done with the t-Student test or analysis of variance (supplemented ments (ABPM). Blood samples were also with a post-hoc test according to Scheffe). If the distribution greatly deviated from the normal, the Mann-Whitney test tained using the Pearson or Spearman method. The relationships between qualitative variables were assessed using multi-way tables and chi-square test according to Pearson. Moreover, variability of individual parameters over time was determined using multilevel mixed effects linear regression. All calculations were carried out by way of help software STATA 13.1 StataCorp Company, LP (United States of America, 2013).

\section{RESULTS}

The study groups and the controls did not differ in respect to age: 38.5 vs 36.4 , respectively. The gender in the study group was similar, but it differed from the controls where $70 \%$ were male ( 40 vs $70 \%$; in $\mathrm{A}+\mathrm{B}$ vs controls, respectively). In Group A, more patients were hypertensive $(47 \%$ vs $35 \% ; p<0.05)$, and less were smokers, than were those composing Group B (23\% vs 45\%; $<<0.05)$. The average daily systolic and diastolic blood pressure did not change significantly, and blood pressure was satisfactorily monitored $(<140 / 90 \mathrm{mmHg})$.

In the study groups $(\mathrm{A}+\mathrm{B})$, statistically significant changes in biochemistry were observed (table 2), however, renal function remained stable during the whole study period. Furthermore, the concentration of ADMA at various points during the observation period did not differ between Group A and B, yet, the relationships between plasma was applied. Correlations between variables were ascer-

Table 2. The change of biochemical parameters in 12 months of observation in patients with non-diabetic proteinuria

\begin{tabular}{|c|c|c|c|c|}
\hline parameter & $\begin{array}{l}\text { Mean } \pm \text { SD } \\
1 \text { visit }\end{array}$ & $\begin{array}{l}\text { Mean } \pm S D \\
2 \text { visit }\end{array}$ & $\begin{array}{l}\text { Mean } \pm \text { SD } \\
3 \text { visit }\end{array}$ & $p$ \\
\hline $\begin{array}{l}\text { ADMA } \\
(\mu \mathrm{mol} / \mathrm{I})\end{array}$ & $\begin{array}{l}\text { n-37 } 0.77 \pm 0.26 \\
\text { A } 0.76 \pm 0.21 \\
\text { B } 0.78 \pm 0.30\end{array}$ & $\begin{array}{ll}n-37 & 0.56 \pm 0.20 \\
\text { A } & 0.54 \pm 0.18 \\
\text { B } & 0.59 \pm 0.21\end{array}$ & $\begin{array}{lll}n-37 & 0.40 \pm 0.14 \\
\text { A } & 0.42 \pm 0.14 \\
\text { B } & 0.38 \pm 0.15\end{array}$ & $\begin{array}{l}<0.001 * \\
<0.001 * \\
<0.001 *\end{array}$ \\
\hline $\begin{array}{l}\text { CRP } \\
(\mathrm{mg} / \mathrm{l})\end{array}$ & $\begin{array}{l}\text { n-37 } 1.66 \pm 1.53 \\
\text { A } 2.13 \pm 1.85 \\
\text { B } 1.27 \pm 0.95\end{array}$ & $\begin{array}{l}\mathrm{n}-371.26 \pm 1.02 \\
\text { A } 1.17 \pm 0.6 \\
\text { B } 1.32 \pm 1.10\end{array}$ & $\begin{array}{l}n-371.19 \pm 0.89 \\
\text { A } 1.46 \pm 0.95 \\
\text { B } 0.98 \pm 1.21\end{array}$ & $\begin{array}{l}0.020 * \\
0.058^{*} \\
0.121\end{array}$ \\
\hline $\begin{array}{l}\text { Albumin } \\
\text { (g/dl) }\end{array}$ & $\begin{array}{l}\mathrm{n}-3737.13 \pm 9.16 \\
\text { A } 43.88 \pm 4.43 \\
\text { B } 31.40 \pm 8.19\end{array}$ & $\begin{array}{l}\text { n-37 } 42.88 \pm 7.19 \\
\text { A } 45.8 \pm 5.48 \\
\text { B } 40.57 \pm 7.66\end{array}$ & $\begin{array}{l}n-37 \quad 41.23 \pm 5.45 \\
\text { A } 43.75 \pm 3.60 \\
\text { B } 39.00 \pm 5.91\end{array}$ & $\begin{array}{l}<0.001^{* *} \\
0.346 \\
<0.001^{* *}\end{array}$ \\
\hline $\begin{array}{l}\text { Fibrinogen } \\
(\mathrm{g} / \mathrm{l})\end{array}$ & $\begin{array}{l}\text { n-37 } 4.93 \pm 1.90 \\
\text { A } 4.26 \pm 1,85 \\
\text { B } 5.51 \pm 1.79\end{array}$ & $\begin{array}{l}\mathrm{n}-373.83 \pm 1.10 \\
\text { A } 3.83 \pm 1.0 \\
\text { B } 3.82 \pm 1.20\end{array}$ & $\begin{array}{l}\text { n-37 } 3.79 \pm 1.18 \\
\text { A } 3.61 \pm 0.89 \\
\text { B } 3.94 \pm 1.39\end{array}$ & $\begin{array}{r}<0.001^{*} \\
0.028^{* *} \\
<0.001^{* *}\end{array}$ \\
\hline $\begin{array}{l}\text { Creatinine } \\
(\mathrm{mg} / \mathrm{dl})\end{array}$ & $\begin{array}{ll}n-37 & 1.14 \pm 0.37 \\
\text { A } & 1.20 \pm 0.45 \\
\text { B } & 1.09 \pm 0.29\end{array}$ & $\begin{array}{l}n-371.17 \pm 0.44 \\
\text { A } 1.28 \pm 0.59 \\
\text { B } 1.09 \pm 0.28\end{array}$ & $\begin{array}{l}n-37 \quad 1.15 \pm 0.52 \\
\text { A } 1.25 \pm 0.65 \\
\text { B } 1.06 \pm 0.36\end{array}$ & $\begin{array}{l}0.793 \\
0.500 \\
0.376\end{array}$ \\
\hline $\begin{array}{l}\text { eGFR (MDRD) } \\
\mathrm{ml} / \mathrm{min} / 1.73 \mathrm{~m}^{2}\end{array}$ & $\begin{array}{l}\text { n-37 } 80.85 \pm 26.57 \\
\text { A } 75.12 \pm 26.47 \\
\text { B } 81.4 \pm 28.65\end{array}$ & $\begin{array}{l}\text { n-37 } 80.74 \pm 26.85 \\
\text { A } 73.80 \pm 27.61 \\
\text { B } 80.95 \pm 23.56\end{array}$ & $\begin{array}{l}\text { n-37 } 81.47 \pm 27.17 \\
\text { A } 77.56 \pm 29.70 \\
\text { B } 85.56 \pm 28.45\end{array}$ & $\begin{array}{l}0.126 \\
0.328 \\
0.230\end{array}$ \\
\hline $\begin{array}{l}\text { eGFR } \\
\text { (CKD-EPI) } \\
\mathrm{ml} / \mathrm{min} / 1.73 \mathrm{~m}^{2}\end{array}$ & $\begin{array}{l}n-3783.80 \pm 26.1 \\
\text { A } 77.82 \pm 24.97 \\
\text { B } 84 \pm 27.55\end{array}$ & $\begin{array}{l}n-3783.68 \pm 26.78 \\
\text { A } 76.47 \pm 27.99 \\
\text { B } 84.84 \pm 24.76\end{array}$ & $\begin{array}{l}\text { n-37 } 84.44 \pm 27.03 \\
\text { A } 80.38 \pm 29.81 \\
\text { B } 88.11 \pm 28\end{array}$ & $\begin{array}{l}0.055^{*} \\
0.302 \\
0.102\end{array}$ \\
\hline $\begin{array}{l}\text { Total cholesterol } \\
(\mathrm{mg} / \mathrm{dl})\end{array}$ & $\begin{array}{l}\text { n-37 } 285.24 \pm 110.79 \\
\text { A } 239.47 \pm 45.77 \\
\text { B } 324.15 \pm 134.25\end{array}$ & $\begin{array}{ll}\text { n-37 } & 219.00 \pm 49.0 \\
\text { A } 222.53 \pm 34.53 \\
\text { B } 216.21 \pm 58.80\end{array}$ & $\begin{array}{lll}\text { n-37 } & 210.79 \pm 52.71 \\
\text { A } & 222.53 \pm 34.53 \\
\text { B } & 209.94 \pm 68.96\end{array}$ & $\begin{array}{r}<0.001^{*} \\
0.012^{* *} \\
<0.001^{* *}\end{array}$ \\
\hline $\begin{array}{l}\text { Triglicerydes } \\
(\mathrm{mg} / \mathrm{dl})\end{array}$ & $\begin{array}{l}\text { n-37 238.81 } 247.46 \\
\text { A } 192.12 \pm 166.79 \\
\text { B } 278.50 \pm 298.32\end{array}$ & $\begin{array}{ll}\text { n-37 } 195.73 \pm 217.22 \\
\text { A } 267.67 \pm 315.27 \\
\text { B } 138.95 \pm 38.47\end{array}$ & $\begin{array}{|ll|}\text { n-37 } & 154.53 \pm 107.74 \\
\text { A } & 177.22 \pm 145.05 \\
\text { B } & 134.33 \pm 55.23\end{array}$ & $\begin{array}{l}0.001^{*} \\
0.114 \\
0.001^{*}\end{array}$ \\
\hline $\begin{array}{l}\text { HDL Cholesterol } \\
(\mathrm{mg} / \mathrm{dl})\end{array}$ & $\begin{array}{l}n-37 \quad 51.73 \pm 16.29 \\
\text { A } 45.82 \pm 11.24 \\
\text { B } 56.75 \pm 18.40\end{array}$ & $\begin{array}{l}n-3756.29 \pm 24.25 \\
\text { A } 44.86 \pm 14.26 \\
\text { B } 65.31 \pm 26.93\end{array}$ & $\begin{array}{l}n-3752.68 \pm 21.68 \\
\text { A } 47.87 \pm 15.57 \\
\text { B } 56.94 \pm 25.65\end{array}$ & $\begin{array}{l}0.143 \\
0.445 \\
0.053 * *\end{array}$ \\
\hline $\begin{array}{l}\text { Daily protein } \\
\text { urinary excretion } \\
(\mathrm{g} / \mathrm{d})\end{array}$ & $\begin{array}{l}\text { n-37 } 4.13 \pm 4.34 \\
\text { A } 1.53 \pm 0.96 \\
\text { B } 6.3 \pm 4.87\end{array}$ & $\begin{array}{l}\text { n-37 } 1.76 \pm 3.23 \\
\text { A } 1.23 \pm 0.88 \\
\text { B } 2.19 \pm 4.26\end{array}$ & $\begin{array}{lll}n-37 & 1.55 \pm 1.91 \\
\text { A } & 1.01 \pm 0.86 \\
B & 2.04 \pm 2.44\end{array}$ & $\begin{array}{r}<0.001^{*} \\
0.005^{*} \\
<0.001^{*}\end{array}$ \\
\hline
\end{tabular}

Abbreviations: CRP - C-reactive protein, eGFR - estimated glomerular filtration rate, $\mathrm{HDL}$ - high density lipoprotein. Conversion factors to SI units are as follows: for total cholesterol, LDL cholesterol 0.0259 for creatinine 88.4, for triglycerides 0.0114

* method of analysis of variance - model assuming a linear variation

** method of analysis of variance - model assuming a quadratic function variation 
ADMA and TCh, daily urine protein excretion, CRP and fibrinogen were statistically significant.

\section{DISCUSSION}

The risk of cardiovascular events in patients with chronic kidney disease (CKD) is higher than in the general population, and is enhanced in patients in the early stages of CKD. Several potential factors have been found which could explain this phenomenon. These include: dysfunction of the endothelium, vascular calcification, oxidative stress and inflammation [5]. Endothelial dysfunction is now considered a basic process responsible for the development of atherosclerosis [1]. In contrast, albuminuria is also a marker of renal damage and vascular injury [13]. Paisley et al. demonstrated that endothelial dysfunction is present in patients with asymptomatic proteinuria, and attributed it to its impact on the process of nitrogen oxide formation in the endothelium [11]. On the other hand, in patients with nephrotic syndrome, lipids disorders coexist which can potentiate endothelial dysfunction.

ADMA level can increase in CKD because of the impaired glomerular filtration rate. The growth comes primarily due to the reduced activity of the enzyme dimethylarginine dimethylaminohydrolase (DDAH), and increased protein arginine $\mathrm{N}$-methyltransferase (PRMT) activity. In patients with severe proteinuria, the increase of ADMA is associated with a higher turnover of the protein [15]. Data on the relationship of proteinuria with ADMA, and ADMA impact on cardiovascular risk is scarce. Elevated ADMA levels seem to be a "link" between proteinuria, endothelium dysfunction and atherosclerosis complications.

In our study, patients suffering from ChGN at early CKD stages (mean eGFR $>80 \mathrm{ml} / \mathrm{min} / 173 \mathrm{~m}^{2}$; mean proteinuria $4.13 \mathrm{~g} /$ day) had elevated levels of ADMA plasma concentration (mean $0.77 \mu \mathrm{mol} / 1)$, in comparison with the control group (mean $0.56 \mu \mathrm{mol} / \mathrm{l})$. Hence, a significant correlation between the concentration of ADMA and proteinuria has been demonstrated. It is worth mentioning that Fliser $e t$ al. noticed a significant positive correlation between the concentration of ADMA and proteinuria in CKD patients with both mild impairment of glomerular filtration rate and proteinuria (1 g/day) [6]. Additionally, Caglar et al. found a significant relationship between the concentration of ADMA and proteinuria in patients with non-diabetic proteinuria and normal kidney function [3]. These results were similar to that of our study.

Many reports have shown the efficacy of RAAS blockers in reducing proteinuria in renal diseases and in slowing the progression of renal dysfunction [9]. However, only a few studies have demonstrated RAAS blocker efficacy in normotensive patients with CKD. Still, Makino et al. reported that sartans reduce the transition to overt nephropathy in normotensive diabetic patients, suggesting that sartans have favorable BP-independent effects on CKD [10]. In addition, Web et al. demonstrated that RAAS blockers effectively reduced proteinuria in normotensive children with CKD [14].
Fujii et al. published a study that concluded that in patients with ChGN and normal renal function serum, ADMA levels and urinary protein excretion significantly decreased after receiving treatment with RAAS blockers The drugs, however, did not have any influence on blood pressure. These findings suggest that RAAS blockers improve the NO system in normotensive patients with CKD [7]. In the presented study, after six months of treatment (RAAS blockers alone or with immunosupressives), a decrease of ADMA to a level comparable with the control group, was evident. What is more, after the following six months, a further reduction of ADMA was observed.

In the present study, we saw a positive correlation between ADMA and serum total cholesterol, as well as a significant reduction of total cholesterol (groups A+B: 285.24 vs $198,5 \mathrm{mg} / \mathrm{dl} ; \mathrm{p}<0.001)$. These results are consistent with those of Böger et al., who, for the first time, showed a significant positive correlation between serum ADMA and hyperlipidemia in patients with asymptomatic hypercholesterolemia and without other comorbidities [2]. Data concerning the relationship between the concentration of ADMA and the indicator of inflammation status (CRP) have also been confirmed in patients with ESRD and chronic cytomegalovirus infection [9]. Furthermore, Cagler et al. have shown a relationship between the concentration of ADMA and the level of CRP in patients with normal renal functions and non-diabetic proteinuria [3]. Our study confirms these findings as, among our study participants, a significant correlation between the concentration of ADMA and both CRP and fibrinogen levels was found.

Therefore, it can be assumed that in patients suffering from hypertension, high blood ADMA concentration results from the impaired metabolism of ADMA within various organs, rather than that hypertension being induced by increased ADMA concentration. Fujimi-Hayashida et al., in patients with IgA nephropathy, demonstrated the correlation of ADMA with proteinuria and kidney damage in biopsy, but not with both systolic and diastolic blood pressure [8]. The authors also suggest that ADMA be used as an indicator of glomerular and interstitial damage evaluated in renal biopsy. Fujii et al. confirm this, as they saw, in patients with ChGN and normal renal function, no correlation between blood pressure and ADMA level [7]. Similar results in this matter were achieved in our study. At each point of observation, the average blood pressure was in the normal range, both in the whole studied group of patients, as well as in the groups evaluated separately during the 12 months follow-up. Moreover, in all patients, the treatments resulted in a wellregulated blood pressure during the day and night, respectively. Simultaneously, during the observation, a significant decrease in ADMA plasma concentrations was observed. The ADMA level also did not correlate with average daily, systolic or diastolic blood pressure.

\section{CONCLUSIONS}

In summary, even taking into account all the study limitations (a small study population, a short time of observation), in our study, we have demonstrated the presence of 
a significant, higher, ADMA concentration in the plasma of patients suffering from ChGN before treatment, when compared with a healthy group. What is more, treatment with RAAS blockers (alone or with immunosupression) was associated with a significant reduction of both plasma ADMA concentration and urinary protein excretion, without any influence on the blood pressure control.

\section{REFERENCES}

1. Bonetti P.O., Lerman L.O., Lerman A. Endothelial dysfunction: a marker of atherosclerotic risk. Arterioscler Thromb Vasc Biol., 23,168-175, 2003.

2. Böger R.H. et al. Asymmetric Dimethylarginine (ADMA): A Novel Risk Factor for Endothelial Dysfunction, Its Role in Hypercholesterolemia. Circulation, 98, 1842-1847, 1998.

3. Caglar K. et al. ADMA, proteinuria, and insulin resistance in nondiabetic stage I chronic kidney disease. Kidney Int., 70 ,781-787, 2006.

4. Colonna De Gennaro V. et al. Asymmetric dimethylarginine (ADMA): an endogenous inhibitor of nitric oxide synthase and a novel cardiovascular risk molecule. Med Sci Monit., 15, RA91$101,2009$.

5. Deckert T., Feldt-Rasmussen B., Borch-Johnsen K. Albuminuria reflects widespread vascular damage. The Steno hypothesis. Diabetologia, 32, 219-226, 1989.
6. Fliser D.et al. Asymmetric dimethylarginine and progression of chronic kidney disease: the mild to moderate kidney disease study. J Am Soc Nephrol., 16, 2456-2461, 2005.

7. Fujii H. et al. Renin-Angiotensin System Inhibitors Reduce Serum Asymmetric Dimethylarginin Levels and Oxidative Stress in Normotensive Patients with Chronic Kidney Disease. Nephron Extra, 4, 18-25, 2014.

8. Fujimi-Hayashida A. et al. Association of asymmetric dimethylarginine with severity of kidney injury and decline in kidney function in IgA nephropathy. Am J Nephrol., 33,1-6,2011.

9. Hibbs J.B., Vavrin Z., Taintor R.R. L-Arginine is required for expression of the activated macrophage effector mechanism causing selective metabolic inhibition in target cells. J Immunol.,138: 550-565, 1987.

10. Makino H. et al. INNOVATION Study Group: Prevention of transition from incipient to overt nephropathy with telmisartan in patients with type 2 diabetes. Diabetes Care, 30, 1577-1578, 2007.

11. Paisley K.E. et al. Endothelial dysfunction and inflammation in asymptomatic proteinuria. Kidney Int., 63, 624-633, 2003.

12. Ruggenenti P. et al. Reno-protective properties of ACE-inhibition in non-diabetic nephropathies with non-nephrotic proteinuria. Lancet, 354, 359-364, 1999.

13. Stehouwer C.D. et al. Microalbuminuria is associated with impaired brachial artery, flow-mediated vasodilation in elderly individuals without and with diabetes: further evidence for a link between microalbuminuria and endothelial dysfunction - the Hoorn Study. Kidney Int., 92, S42-S44, 2004.

14. Webb N.J. et al. Randomized, double-blind, controlled study of losartan in children with proteinuria. Clin J Am Soc Nephrol., 5, 417-424, 2010.

15. Zoccali C., Kielstein J.T. Asymetric dimethylarginine: A new player in the pathogenesis of renal disease? Curr Opin Nephrol Hypertens, 15, 314-320, 2006. 